\title{
Is Materialism All That Bad? Effects on Satisfaction with Material Life, Life Satisfaction, and Economic Motivation
}

\author{
M. Joseph Sirgy • Eda Gurel-Atay • Dave Webb • Muris Cicic • \\ Melika Husic-Mehmedovic • Ahmet Ekici • Andreas Herrmann • \\ Ibrahim Hegazy $\cdot$ Dong-Jin Lee $\cdot$ J. S. Johar
}

Accepted: 11 September 2011/Published online: 12 October 2011

(C) Springer Science+Business Media B.V. 2011

\begin{abstract}
The literature in economic psychology and quality-of-life studies alludes to a negative relationship between materialism and life satisfaction. In contrast, the macroeconomic literature implies a positive relationship between material consumption and economic growth. That is, materialism may be both good and bad. We develop a model that reconciles these two contrasting viewpoints by asserting that materialism may lead to life dissatisfaction when materialistic people evaluate their standard of living using fantasy-based expectations (e.g., ideal expectations), which increases the likelihood that they would evaluate their standard of living negatively. In turn, dissatisfaction with standard of living increases the likelihood that they would evaluate their life negatively. However, materialistic people who evaluate their standard of living using reality-based expectations
\end{abstract}

\footnotetext{
M. Joseph Sirgy ( $\bowtie)$

Department of Marketing, Pamplin College of Business, Virginia Polytechnic Institute and State University, Blacksburg, VA 24061-0236, USA

e-mail: sirgy@vt.edu

E. Gurel-Atay

Department of Marketing, Lundquist College of Business, University of Oregon,

Eugene, OR 97403, USA

e-mail: egurelat@uoregon.edu

D. Webb

Business School, University of Western Australia, 35 Stirling Highway, Crawley, WA 6009, Australia e-mail: dave.webb@uwa.edu.au
}

M. Cicic - M. Husic-Mehmedovic

Department of Marketing, School of Economics and Business, University of Sarajevo,

Trg oslobodenja, Alija Izetbegovic 1, 71000 Sarajevo, Bosnia-Herzegovina

e-mail: muris.cicic@efsa.unsa.ba

M. Husic-Mehmedovic

e-mail: melika.husic@efsa.unsa.ba

A. Ekici

Faculty of Business Administration, Bilkent University, 06800 Bilkent, Ankara, Turkey

e-mail: ekici@bilkent.edu.tr 
(e.g., ability expectations) are likely to feel more economically motivated than their nonmaterialistic counterparts, and this economic motivation is likely to contribute significantly and positively to life satisfaction. Survey data were collected from seven major cities each in a different country (Australia, Bosnia/Herzegovina, Germany, Egypt, Korea, Turkey, and the USA) using a probability sample (cluster sampling method involving income stratification). The results provide support for the model. The economic public policy implications concerning how people evaluate their standard of living using ability-based expectations are discussed in the context of the ideals of meritocracy.

Keywords Materialism - Evaluation of standard of living - Satisfaction with material life · Economic motivation - Life satisfaction - Quality of life · Meritocracy

\title{
1 Introduction
}

The economics literature implies that materialism contributes significantly to a positive quality of life (e.g., Arndt 1981; Britton 2010; Bunker and Ciccantell 2003; Fata-Villafranca and Saura-Bacaicoa 2004; Fernandez 2007; Kilbourne et al. 1997). In contrast, quality-of-life studies have demonstrated that materialism contributes significantly to a negative quality of life (see literature reviews on materialism by Larsen et al. 1999; Richins and Rudmin 1994; Robert and Clement 2007). Therein lies a paradox!

If materialism contributes negatively to quality of life, then the question we should pose is: How? More specifically we could pose the question: what is the mediating mechanism that makes materialism a negative factor in people's perception of their quality of life (i.e., life satisfaction)? Perhaps this can be explained with the way materialistic people evaluate their standard of living (SOL). For instance, materialistic people evaluate their SOL using inflated and unrealistic expectations (ideal-based expectations) that induce feelings of dissatisfaction with their material life, which in turn spills over to life dissatisfaction. This is one hypothesis that is tested in the study reported in this paper.

But then if we take this further, how can we reconcile that materialism is positively correlated with economic motivation (e.g., Baudrillard 1997; Belk 1989; Cherrington 1980; Furnham 1990, Ch. 7; Schor 1998; Scitovsky 1986), and that economic motivation contributes to quality of life (e.g., Layton 2009; McClelland 1961; McClelland and Winter

\author{
A. Herrmann \\ Department of Marketing, Audi Lab for Market Research, St. Gallen University, Forschungsstelle fur \\ Business Metrics, Guisanstrasse 1a, 9000 St. Gallen, Switzerland \\ e-mail: andreas.herrmann@unisg.ch \\ I. Hegazy \\ Department of Marketing, American University in Cairo, 113 Kasr El-Aini, Cairo 11511, Egypt \\ e-mail: hegazy@aucegypt.edu \\ D.-J. Lee \\ Department of Marketing, Yonsei University, 262 Seongsan-ro, Seodaemun-gu, Seoul 120-749, Korea \\ e-mail: djlee81@yonsei.ac.kr

\section{J. S. Johar} \\ Department of Marketing, California State University at San Bernardino, 5500 University Pkwy, \\ San Bernardino, CA 92407, USA \\ e-mail: vjohar@csusb.edu
}


1969)? Perhaps not all materialistic people evaluate their SOL using inflated and unrealistic expectations, and those who use realistic expectations (e.g., ability-based expectations) tend to feel more economically motivated than their non-materialistic counterparts. In turn, economic motivation for these materialistic people is likely to contribute positively to their life satisfaction. This is another set of hypotheses that are tested in the study reported here.

Specifically, materialism can be construed as "bad" because it may lead to life dissatisfaction for some. But on the another hand, materialism can be viewed as "good" because it may make some people economically motivated, which in turn may contribute to not only life satisfaction but also economic growth, which is often viewed as a positive societal outcome.

Our goal with this paper is to advance theory relating to the link between materialism and life satisfaction by developing a theoretical model that explains this paradox. Explaining this paradox may provide further insight to the debate concerning the positive and negative effects of economic development on quality of life. This debate can further inform public policy regarding how economic policies and programs should be formulated to maximize the contribution of the economics discipline to quality of life studies.

\section{Conceptual Development}

Materialistic people believe that the continued acquisition of possessions will lead to greater happiness and satisfaction in life, and that lack of possessions will lead to dissatisfaction in life. Ironically, much empirical research has shown the opposite. In other words, dissatisfaction with life, not satisfaction, is the result of a materialistic orientation (e.g., Belk 1984, 1985; Burroughs and Rindfeisch 2002; Dawson and Bamossy 1991; Keng et al. 2000; La Barbera and Gurhan-Canli 1997; Richins 1987; Richins and Dawson 1992; Wright and Larsen 1993).

At least two explanations account for the negative relationship between materialism and life satisfaction: top-down theory of subjective well-being and bottom-up theory of subjective well-being. Quality-of-life researchers have consistently adopted these two theories to explain the determinants of life satisfaction (see Diener 1984; Diener et al. 1999 for a review of the literature). The top-down theory of subjective well-being states that life satisfaction is influenced by personality or dispositional factors (e.g., self-esteem, alienation, optimism, pessimism, neuroticism, and introversion/extraversion). In contrast, the bottom-up theory of subjective well-being argues that life satisfaction is influenced by situational factors that impact the sense of well-being in specific life domains (e.g., satisfaction with SOL, job, family, leisure, neighborhood, community).

In terms of the former (top-down theory), Belk (1985) suggested that materialistic people are usually possessive, non-generous, and envious. These are dispositional factors, reflecting a tendency to experience negative emotions. Thus, one can argue that the negative affect related to dispositional materialism influences life satisfaction (i.e., materialism negatively influences life satisfaction).

In terms of the latter (bottom-up theory), this theory states that life satisfaction is greatly influenced by evaluations of important life domains. Specifically, positive and negative affect are invested in life domains capturing certain types of emotional experiences such as family life, leisure life, love life, work life, social life, spiritual life, and so on. One important life domain is material life (or SOL assessed in material terms). The material life domain houses emotional reactions related to material possessions, household income, 
savings, investment, and other material resources related to personal wealth. Thus, life satisfaction/dissatisfaction judgments are directly influenced by how one feels about important life domains such as material life. Sirgy et al. (1998) demonstrated that the negative relationship between materialism and life satisfaction is mediated by evaluations of SOL. Specifically, the study found that materialistic people are less satisfied with their material possessions and, in turn, less satisfied with life than non-materialistic people.

Sirgy (1998) proposed that materialistic people have lower SOL evaluations because they have inflated expectations and because they frequently employ these inflated standards when evaluating their SOL, whereas non-materialistic people have more realistic expectations. He elaborated on various types of expectations or standards of comparison and how materialistic people (compared to non-materialistic people) use these expectations. He delineated six types of expectations: expectations based on (1) their ideal view of SOL, (2) what they feel they deserve in terms of financial resources, (3) what they need to maintain a certain lifestyle, (4) what they have predicted all along in attaining a certain level of personal wealth, (5) how far they have progressed in relation to what they had in the past, and (6) how much personal wealth they were able to amass based on their ability (i.e., their educational background, inheritance, socio-economic status, etc.). Sirgy argued that materialistic people tend to make more frequent evaluations of their SOL using ideal, deserved, and need-based expectations than non-materialistic people. Evaluating SOL using ideal, deserved, and need-based expectations is likely to result in negative evaluations of SOL, which in turn, contribute to feelings of life dissatisfaction. Conversely, nonmaterialistic people tend to make more frequent evaluations of their SOL using past, predictive, and ability-based expectations. Evaluating SOL using past, predictive, and ability-based expectations is likely to result in positive evaluations, which in turn contribute to feelings of life satisfaction.

In our study, we focus on the ideal and ability-based expectations proposed by Sirgy (1998). We endorse Sirgy's notion that materialistic people who frequently use inflated and unrealistic expectations of their SOL (such as ideal expectations) are likely to feel dissatisfied with their SOL, which in turn spills over to life dissatisfaction. These theoretical links are shown in our model (see Fig. 1) as Hypotheses 1-3.

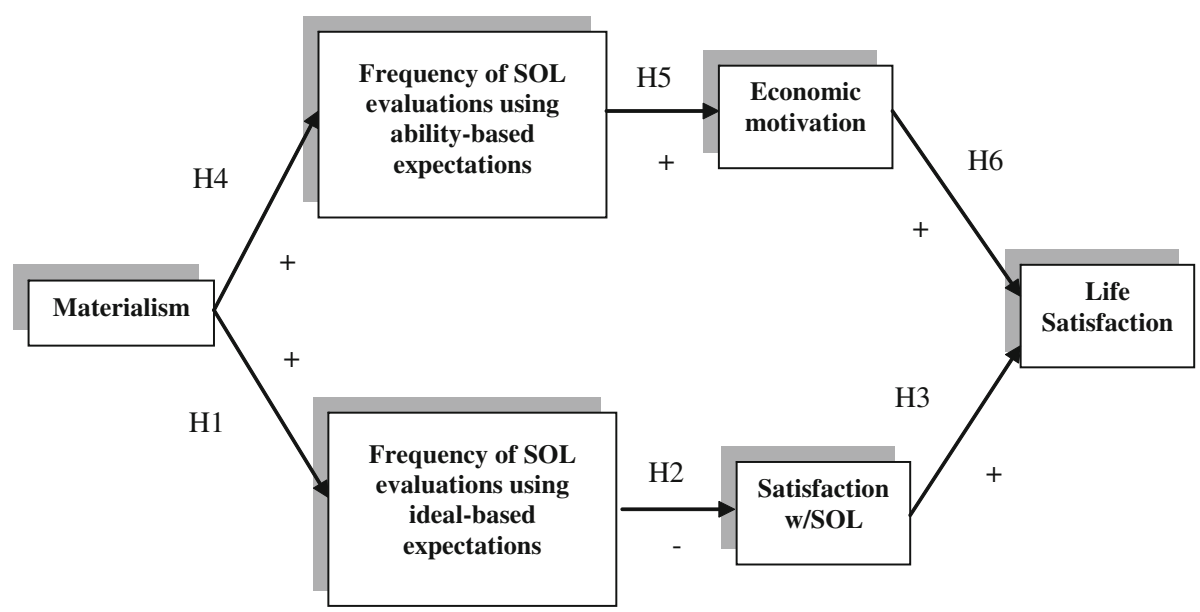

Fig. 1 The conceptual model 
An example of an ideal expectation is "I want to be very rich." People are likely to feel disappointed with their SOL when they frequently evaluate their current state of affairs against such ideal standards. Materialistic people are likely to make more frequent evaluations of SOL using ideal-based expectations than non-materialistic people (Hypothesis 1). Thus, Hypothesis 1 is essentially based on Sirgy's (1998) thesis. Also consistent with Sirgy's (1998) thesis, our second hypothesis states that the greater the frequency of evaluations of SOL based on ideal expectations, the lower the overall satisfaction with SOL (Hypothesis 2). Our third hypothesis posits that the more a person feels dissatisfied with his or her SOL the more he or she is likely to feel dissatisfied with his or her life at large (Hypothesis 3). There is much evidence in the quality-of-life literature suggesting that satisfaction with material life contributes positively and substantially to life satisfaction (e.g., Diener and Fujita 1995; Gerdtham and Johannesson 2001; Peiro 2006; Winkelmann and Winkelmann 1998).

However, contrary to Sirgy (1998), we believe that materialistic people also frequently evaluate their SOL using realistic expectations based on their ability to generate income. Materialistic people who frequently engage in this type of SOL evaluations are likely to feel more economically motivated than their non-materialistic counterparts. In other words, we do not necessarily think that non-materialistic people make more frequent SOL evaluations using ability-based expectations than materialistic people. Rather, we posit that non-materialistic people are not likely to make frequent SOL evaluations using any kind of expectation, period. This may be due to the fact that they do not place much salience on their material life (e.g., Belk 1984, 1985, 1989; Richins 1987, 1994a, b; Richins and Dawson 1992; Richins and Rudmin 1994). If they regard their material life as less important, they are not likely to engage in frequent evaluations of their SOL. Rather, they are more likely to evaluate other life domains they regard as important such as family life, social life, spiritual life, and community life (e.g., Kasser and Ryan 1993). Hence, only materialistic people are likely to frequently evaluate their material life (i.e., SOL) using various types of expectations (ideal expectations, ability expectations, etc.).

While it may be true that materialistic people frequently evaluate their SOL using ideal expectations, it is our position that materialistic people often use both ideal and abilitybased standards. Some may use ideal expectations more frequently (especially when they compare their SOL in certain situations that may prompt ideal standards such as watching the rich and famous on television), while others may use realistic (ability-based) standards more frequently (especially in situations that may prompt ability standards such as situations related to achievement). Materialistic people are likely to make SOL evaluations based on ability expectations when they perceive that their economic aspirations are likely to be achieved as a direct function of their hard work. They believe that their economic goals are challenging yet attainable with hard work. Thus, they are likely to be motivated to achieve their SOL goals. In this case, ability-based expectations are used as an economic goal (Szymanski and Henard 2001). In contrast, materialistic people are also likely to make SOL evaluations based on ideal-expectations when they believe that their economic aspirations may be unattainable. When the SOL is perceived to be too high and unattainable, they are more likely to use ideal expectations as a standard of comparison in their evaluations of their SOL (Szymanski and Henard 2001). In other words, we believe that there are two types of materialistic people: those who frequently evaluate their SOL using unrealistic and inflated (ideal-based) expectations and those who frequently evaluate their SOL using realistic and non-inflated (ability-based) expectations. Hypothesis 1 focuses on one segment of materialistic people - those who frequently make SOL judgments based on ideal expectations. Materialistic people in this segment tend to make comparisons with 
other wealthy people, and they strive to become as wealthy (or more wealthy) than their aspiration group.

Hypothesis 4 focuses on the other segment-those who frequently make SOL judgments based on ability expectations. Materialistic people in this segment evaluate their own SOL based on realistic expectations; they anticipate improvement in their SOL based on an assessment of their abilities and their current situation. Therefore, we also expect materialism to be a positive predictor of frequency of SOL evaluations using ability-based expectations (Hypothesis 4). In sum, we do expect that materialism to be positively related to both types of expectations (i.e., frequency of SOL evaluations based on both ideal and ability expectations).

Sirgy (1998) would expect that materialism would be a negative predictor of frequency of SOL evaluations based on ability expectations. We part company with Sirgy (1998) in regards to this hypothesis. Furthermore, we believe that those who make frequent SOL evaluations using ability-based expectations are likely to feel more economically motivated than those who do not (Hypothesis 5). Consistent with experts on the subject, we define economic motivation as the drive to achieve economic goals (McClelland 1961; McClelland and Winters 1969). The hypothesized effect may be due to self-efficacy (e.g., Bandura 1997; Diener and Fujita 1995; Pinquart and Sörensen 2000). Self-efficacy reflects the person's confidence in his ability to take on and put on the necessary effort to succeed at economic tasks. People who frequently evaluate their SOL positively based on their ability to get things done are likely to feel more economically motivated than those who do not.

Finally, we hypothesize that the greater the economic motivation, the greater the life satisfaction (Hypothesis 6). Economic motivation is likely to increase life satisfaction because economic motivation imbues people with the feelings of economic optimism and confidence in their progress towards their economic goals. Thus, those who are economically motivated are likely to experience feelings of happiness because of their optimism, confidence in their ability to reach their goals, and their anticipation of the fruits of their labor (Van Boven and Ashworth 2007). In other words, people who feel more economically motivated are likely to experience a high level of optimism and hope, important ingredients in life satisfaction (Seligman 1998, 2002).

\section{Method}

\subsection{Sampling and Data Collection}

To test the conceptual model shown in Fig. 1, a consumer survey was conducted in a city in each of seven countries in 2007: Australia, Bosnia and Herzegovina, Germany, Egypt, Korea, Turkey, and the United States. Our goal in collecting data from different countries is to generate adequate variance in the constructs, not to conduct cross-cultural comparisons.

The survey questionnaire was translated to local languages and then back-translated to English by bilingual speakers in each country. Thereafter, a stratified/cluster sampling technique was used to collect the data. Specifically, each city was divided into neighborhoods and these neighborhoods were categorized as being of high, medium, or low income. After selecting two sample neighborhoods from each category, a systematicrandom sampling procedure was used to collect the survey data. Once a potential respondent agreed to complete the questionnaire, the researcher made arrangements to pick 
up the questionnaires 4-7 days later. Overall, 128, 301, 149, 146, 148, 150, and 163 completed questionnaires were collected from the aforementioned countries respectively. Of the 1,185 respondents, approximately $40 \%$ were male and $60 \%$ were female. The age of respondents ranged from 18 to 87 with a mean of 39.37. Forty-seven cases were deleted from the analyses due to significant missing data. Following deletion, the percentage of missing data was less than five percent for each variable and those missing data were randomly distributed. Therefore, they were handled by using the maximum likelihood estimation. Table 1 shows descriptive statistics for each country independently.

\subsection{Measures}

\subsubsection{Materialism}

Richins and Dawson (1992) conceptualized and measured materialism using three subdimensions of materialism: centrality, success, and happiness. However, based on a thorough literature review and a discussion of the shortcomings of current materialism measures (Roberts et al. 2005; Wong et al. 2003), we modified the Richins and Dawson's materialism scale to reflect three sources of motivation: (1) the belief in the notion that material possessions leads to happiness in life (Richins and Dawson 1992); (2) the belief that material possessions symbolize achievement and success, which in turn generate social recognition and status (Richins and Dawson 1992), and (3) the belief that material possessions make people feel distinctive from others, which in turn promote self-regard (Belk 1988; Tian et al. 2001). In other words, it is believed that materialism is best conceptualized in terms of happiness, social recognition, and uniqueness. Therefore, our modified measure of materialism builds on the Richins and Dawson (1992) measure by refining the

Table 1 Descriptive statistics (total sample size $=1,185$ )

\begin{tabular}{|c|c|c|c|c|c|c|c|}
\hline & Australia & $\begin{array}{l}\text { Bosnia and } \\
\text { Herzegovina }\end{array}$ & Germany & Egypt & Korea & Turkey & USA \\
\hline \multicolumn{8}{|l|}{ Gender } \\
\hline $\operatorname{Men}(\%)$ & $57(44.5)$ & $120(39.9)$ & $58(39.7)$ & $54(36.2)$ & $31(20.9)$ & $72(48)$ & 78 (47.9) \\
\hline Women $(\%)$ & $70(54.7)$ & $180(59.8)$ & $88(60.3)$ & $95(63.8)$ & $117(70.1)$ & $76(50.7)$ & $84(51.5)$ \\
\hline Missing (\%) & $1(0.80)$ & $1(0.30)$ & NA & NA & NA & $2(1.3)$ & $1(0.60)$ \\
\hline \multicolumn{8}{|l|}{ Age } \\
\hline Range & $18-81$ & $18-84$ & $18-87$ & $18-65$ & $20-61$ & $18-67$ & $18-83$ \\
\hline Mean & 39.36 & 36.36 & 46.17 & 33.44 & 49.31 & 35.05 & 39.17 \\
\hline \multicolumn{8}{|l|}{ Income level } \\
\hline Low $(\%)$ & $31(24.2)$ & $101(33.6)$ & 49 (33.6) & 49 (32.9) & $49(33.1)$ & $50(33.3)$ & $61(37.4)$ \\
\hline Medium (\%) & $36(28.1)$ & $100(33.2)$ & 48 (32.9) & $50(33.6)$ & $48(32.4)$ & $50(33.3)$ & $50(30.7)$ \\
\hline High $(\%)$ & $61(47.7)$ & $100(33.2)$ & 49 (33.6) & $50(33.6)$ & $51(34.5)$ & (33.3) & $52(31.9)$ \\
\hline \multicolumn{8}{|l|}{ Sample size } \\
\hline $\begin{array}{l}\text { Original sample } \\
\text { size }\end{array}$ & 128 & 301 & 146 & 149 & 148 & 150 & 163 \\
\hline $\begin{array}{l}\text { Number of } \\
\text { deleted cases }\end{array}$ & 21 & NA & NA & NA & 3 & 23 & NA \\
\hline $\begin{array}{l}\text { Final sample } \\
\text { size }\end{array}$ & 107 & 301 & 146 & 149 & 145 & 127 & 163 \\
\hline
\end{tabular}


items related to happiness and social recognition and introducing the new dimension of uniqueness.

In addition to introducing a new dimension (i.e., uniqueness), another goal related to modifying the Richins and Dawson's measure is to ensure a better metric invariance across different countries (cf. Wong et al. 2003). Three items were used to measure each of these dimensions on five-point scales $(1=$ strongly agree, $5=$ strongly disagree $)$. The actual items were as follows:

1. Having luxury items is important to a happy life (Happiness dimension).

2. To me, it is important to have expensive homes, cars, clothes, and other things. Having these expensive items makes me happy (Happiness dimension)

3. Material possessions are important because they contribute a lot to my happiness (Happiness dimension).

4. I love to buy new products that reflect status and prestige (Social recognition dimension).

5. I like to own expensive things more so than most people because this is a sign of success (Social recognition dimension).

6. I feel good when I buy expensive things. People think of me as a success (Social recognition dimension).

7. I enjoy owning expensive things that make people think of me as unique and different (Uniqueness dimension).

8. I usually buy expensive products and brands to make me feel unique and different (Uniqueness dimension).

9. I usually buy expensive things that make me look distinctive (Uniqueness dimension).

\subsubsection{Frequency of Evaluation of Standard of Living with Ideal and Ability-Based Expectations}

A measure of frequency of evaluation of SOL with ideal and ability-based expectations was developed for this study. Respondents were provided with the following prompt: "Most people have strong feelings about their standard of living because they compare their family's current financial situation with different types of standards of comparisons. The questions below are designed to capture the standard of comparison you use in evaluating your family's standard of living." Single items were used to measure ideal and ability-based expectations in evaluating SOL on 10-point scales where 1 means "no, my feelings about my standard of living are not frequently based on this standard of comparison" and 10 means "yes, my feelings about my standard of living are frequently based on this standard of comparison." The actual item capturing frequency of SOL evaluation using ability-based expectations is as follows:

Some compare their family's financial situation based on their education and skills as well as family status and connections. Thus, they may feel happy with their financial situation because their current situation is better than or equal to what they have expected based on their education, skills, family status, and connections; or they may feel less happy because their current situation is significantly below what they expected based on their education, skills, family status, and connections (Abilitybased Expectations of SOL). 
The actual item capturing frequency of SOL evaluation using ideal-based expectations is as follows:

Some people compare their family's financial situation with some ideal goal of wealth they desire to have. Thus, they may feel happy with their financial situation because their current situation meets their ideal goal, or they may feel less happy because their current situation is significantly below their ideal (Ideal-based Expectations of $S O L)$.

\subsubsection{Satisfaction with SOL}

Satisfaction with SOL is considered interchangeably with such constructs as satisfaction with material life (e.g., Richins and Rudmin 1994), subjective economic well-being (e.g., Hayo and Seifert 2003), and satisfaction with material possessions (e.g., Ogden and Venkat 2001). Five semantic-differential items were used to measure satisfaction with SOL (Ogden and Venkat 2001). Specifically, participants were asked to report their feelings about the things their family own, their family's SOL, and their family's financial situation overall on a seven-point scale (happy/angry; good/bad; contented/frustrated; fulfilled/disappointed; and pleased/displeased).

\subsubsection{Economic Motivation}

In the economic psychology literature the term "economic motivation" is considered interchangeably with terms such as "motivation for economic success" (Winter-Ebmer 1994), "need for achievement" (McClelland and Winter 1969), and "work motivation" (Richins and Rudmin 1994). Our economic motivation measure was adapted from the Goal Instability Scale developed by Robbins and Patton (1985). The following five items were used on a five-point scale ( $1=$ strongly disagree; 5 = strongly agree): "(1) I don't seem to make decisions by myself; (2) I seem to lose my sense of direction in life; (3) It's easier for me to start than to finish projects; (4) I don't seem to get going on anything; (5) I don't seem to have the drive to get my work done." The scores are reverse coded to ensure that the higher score are reflective of higher levels of economic motivation, and vice versa. The measure has demonstrated reliability and validity (Robbins and Patton 1985).

\subsubsection{Life Satisfaction}

The short version of the Campbell et al. (1976) scale was used to measure life satisfaction. Specifically, participants were asked to rate their life on the following items by using 7-point semantic-differential descriptors: boring/interesting; useless/worthwhile; full/ empty; discouraging/helpful, and disappointing/rewarding. This measure has a long history of validational use in the quality-of-life literature (Diener 1984; Diener et al. 1999; Keng et al. 2000; Peiro 2006; Sirgy et al. 1998).

\subsubsection{Item Parceling}

Before performing the analyses, item parceling was conducted on materialism. Based on Bagozzi and Heatherton's (1994) recommendation, three dimensions were created for this construct to account for measurement error. Indeed, because materialism is considered a three-factor construct (i.e., happiness, success, and distinctiveness), the indicators of each 
factor were summed to develop three dimensions. These item parcels were used in subsequent analyses.

\section{Results}

The Anderson and Gerbing's (1988) two-step method was applied to estimate the measurement model in the first step and the structural model in the second step. The two-step model is an approach to structural equation modeling (SEM) to separate the measurement failures from the structural ones. In the first step, a confirmatory factor analysis identifies the specification errors in the measurement model (i.e., the model that includes the relations between latent variables and their indicators). Then, in the second step, specifications in the structural equation model (i.e., the model that tests the relations between endogenous and exogenous variables) are identified. Doing so, problems of measurement specification are isolated from the problems of structural specification.

LISREL 8.80 (Joreskog and Sorbom 2006) was used to analyze the covariance matrices in all analyses. Because the goal of this research was neither to look at differences between countries nor to compare countries in terms of the conceptual model, a pooled sample was employed in the analysis. Specifically, our goal in collecting data from different countries was to generate adequate variance in the constructs, not to conduct cross-cultural comparisons.

\subsection{Measurement Model Results}

Prior to conducting a confirmatory factor analysis (CFA), normality of the observed variables was inspected. Some of the variables revealed high skewness and kurtosis values. The Maximum likelihood (ML) estimation method is considered to be very robust even with highly skewed/kurtosis data. However, it is argued that ML produces inflated Chisquare statistics and leads to the rejection of too many true models when the variables are highly non-normal (West et al. 1995). To deal with this problem, the Satorra-Bentler corrected Chi-square was used in all analyses.

To estimate the measurement model, the six constructs, namely materialism, frequency of evaluations of SOL based on ideal expectations, frequency of evaluations of SOL based on ability expectations, satisfaction with SOL, economic motivation, and life satisfaction, were modeled as freely correlated first-order factors with their respective indicators. The Satorra-Bentler scaled Chi-square value for the pooled sample was 581.80 with 158 degrees of freedom. Given the large sample size, the Satorra-Bentler scaled Chi-square value was significant at 0.001 . However, other goodness-of-fit statistics suggested a close and adequate fit to the data with the Root Mean Square Error of Approximation (RMSEA; Steiger and Lind 1980; Browne and Cudeck 1989) $=0.049$, Bentler's (1990) Comparative Fit Index $(\mathrm{CFI})=0.98$, Standardized Root Mean Square Residual (SRMR; Bentler $1995)=0.041$, and Goodness-of-Fit Index (GFI; Joreskog and Sorbom 1984) $=0.94$.

Because the construct validity (the ability of a measurement tool to actually measure the concept being studied) "lies at the very heart of the scientific process" (Churchill 1979, p. 70), the measurement model results were used to establish the construct validity for the measures used in this study. Specifically, two subtests of construct validity (convergent validity and discriminant validity) were used to establish construct validity.

To assess convergent validity, four separate statistics were examined: Average Variance Extracted (AVE), composite reliabilities, coefficient Alphas, and factor loadings. The 
summary of results for tests of convergent validity (internal consistency) for the constructs with multiple items (i.e., materialism, satisfaction with SOL, economic motivation, and life satisfaction) and item parcels (i.e., materialism dimensions) is given in Table 2. To demonstrate convergent validity, the AVE for each construct should be greater than 0.50 and the composite reliability of a factor should be equal to or greater than 0.60 (Fornell and Larcker 1981). All AVE values ranged from 0.530 to 0.702. Composite reliabilities were greater than 0.60 with a range of 0.844-0.921 (excluding parcels). Similarly, coefficient Alphas were relatively high and ranged from 0.838 to 0.921 (excluding parcels). Furthermore, all factor loadings were significant at the 0.05 level. All these results imply that convergent validity (internal consistency) was satisfactory for the constructs in question.

To test for discriminant validity, the squares of correlations between any two constructs were compared with the AVE estimates of those two constructs (Fornell and Larcker 1981). The squared correlations ranged from 0.001 to 0.264 . Because the lowest AVE estimate was 0.530 , the AVE for each construct was greater than its squared correlation with any other construct. Accordingly, discriminant validity was supported.

The results of convergent and discriminant validity tests provided evidence for the construct validity of the measures used in this study.

\subsection{Structural Model Results}

The overall structural model was supported by the data with Satorra-Bentler scaled $\chi^{2}(168$, $\mathrm{N}=1,138)=2,045.44 \quad(p<0.001) ; \quad$ RMSEA $=0.099 ; \quad \mathrm{CFI}=0.91 ; \quad \mathrm{NFI}=0.90 ;$ $\mathrm{SRMR}=0.10$. Furthermore, all path coefficients were significant at the 0.001 level and in expected direction (see Table 3). See correlations matrix in the Appendix.

Our model involves six hypotheses-each is supported as indicated by the significant coefficients shown in parentheses following an articulation of each:

Hypothesis 1 Materialistic people evaluate their SOL more frequently based on ideal expectations than non-materialistic counterparts (standardized estimate $=0.26 ; p<0.001$ ).

Hypothesis 2 The greater the frequency of evaluations of SOL based on ideal expectations, the lower the overall satisfaction with SOL (standardized estimate $=-0.18$; $p<0.001)$.

Table 2 Reliability results $(\mathrm{N}=1,138)$

\begin{tabular}{lllr}
\hline & Coefficient alpha & Composite reliability & AVE \\
\hline Materialism & 0.914 & 0.844 & 0.650 \\
Parcel 1: happiness & 0.834 & 0.836 & 0.630 \\
Parcel 2: social recognition & 0.851 & 0.855 & 0.663 \\
Parcel 3: uniqueness & 0.850 & 0.858 & 0.670 \\
Economic motivation & 0.842 & 0.853 & 0.542 \\
Satisfaction with SOL & 0.921 & 0.921 & 0.702 \\
Life satisfaction & 0.838 & 0.849 & 0.530 \\
\hline
\end{tabular}

$A V E$ average variance explained, $S O L$ standard of living

Composite reliability and AVE values for parcels were calculated from separately conducted confirmatory factor analyses; composite reliability and AVE values for latent constructs were calculated from the final confirmatory factor analysis that included all constructs

Coefficient alpha value for materialism was calculated by using the original items, not parcels 
Table 3 Parameter estimates

\begin{tabular}{lcccc}
\hline Path & ML estimates (SD) & Std. ML estimates & Critical ratio & $p$ values \\
\hline Materialism $\rightarrow$ SOL_Ideal & $0.23(0.03)$ & 0.26 & 8.65 & 0.001 \\
Materialism $\rightarrow$ SOL_Ability & $0.09(0.03)$ & 0.11 & 3.28 & 0.001 \\
SOL_Ideal $\rightarrow$ satisfaction with SOL & $-0.08(0.02)$ & -0.18 & -5.02 & 0.001 \\
SOL_Ability $\rightarrow$ economic motivation & $0.04(0.01)$ & 0.11 & 3.20 & 0.001 \\
Satisfaction with SOL $\rightarrow$ life sat & $0.54(0.03)$ & 0.79 & 16.90 & 0.001 \\
Economic motivation $\rightarrow$ life sat & $0.57(0.04)$ & 0.62 & 12.97 & 0.001 \\
\hline
\end{tabular}

$M L$ estimates (SD) unstandardized maximum likelihood estimates (standard deviation), Std. ML estimates completely standardized maximum likelihood estimates, SOL standard of living, SOL_Ideal idealbased expectations of SOL, SOL_Ability ability-based expectations of SOL, Life Sat life satisfaction

Hypothesis 3 The more a person feels dissatisfied with his or her SOL, the more he or she is likely to feel dissatisfied with his or her life at large (standardized estimate $=0.79$; $p<0.001)$.

Hypothesis 4 Materialistic people evaluate their SOL more frequently based on ability expectations than non-materialistic counterparts (standardized estimate $=0.11$; $p<0.001)$.

Hypothesis 5 People who make frequent SOL evaluations using ability-based expectations are likely to feel more economically motivated than those who do not (standardized estimate $=0.11 ; p<0.001)$.

Hypothesis 6 The greater the economic motivation, the greater the life satisfaction ( standardized estimate $=0.62 ; p<0.001$ ).

\section{Discussion}

The study results provide support for the predictive effects of materialism on satisfaction with SOL, life satisfaction, and economic motivation as mediated by frequency of SOL evaluations based on ability versus ideal expectations. Specifically, the results support the hypotheses that materialism increases the frequency of evaluations based on inflated and unrealistic expectations of wanting to be rich (Hypothesis 1). This hypothesis is essentially consistent with Sirgy's (1998) theory of materialism and quality of life. The study findings also support the notion that the greater the frequency of evaluations of SOL based on ideal expectations, the lower the overall satisfaction with SOL (Hypothesis 2). Again, this hypothesis is consistent with Sirgy (1998). The results also supported the hypothesis that the more a person feels dissatisfied with his or her SOL, the more he or she is likely to feel dissatisfied with his or her life at large (Hypothesis 3). This finding is consistent with much of the research in quality-of-life studies that suggests that satisfaction with material life contributes positively and substantially to life satisfaction (e.g., Diener and Fujita 1995; Gerdtham and Johannesson 2001; Peiro 2006; Winkelmann and Winkelmann 1998). Findings related to Hypotheses 1-3 combined are also consistent with a recent study examining the relationship between frequency of social comparisons and subjective wellbeing (Fujita 2008). This study demonstrated that people experiencing low levels of 
subjective well-being tend to engage in frequent social comparisons, more so than those experiencing high levels of subjective well-being. Those who engage in frequent comparisons were also found to score highly on measures of neuroticism, a personality trait negatively related with subjective well-being (Diener 1984; Diener et al. 1999).

The study findings provided support to the notion that materialism is also a positive predictor of SOL evaluations using ability-based expectations (Hypothesis 4). In other words, high materialistic people do not only evaluate their SOL using ideal expectations but also ability expectations, and as such this contributes to economic motivation (Hypothesis 5). As explained earlier, this effect may be due to self-efficacy (e.g., Bandura 1997; Diener and Fujita 1995; Pinquart and Sörensen 2000). In other words, people who evaluate their SOL positively based on their ability to get things done are likely to feel more economically motivated than those who do not. Furthermore, the data support the hypothesis that economic motivation contributes to life satisfaction (Hypothesis 6), which is consistent with much research in subjective well-being (e.g., Seligman 1998, 2002).

The study findings underscore the assertion that materialism is different from material well-being. First, material well-being plays a significant role in life satisfaction (Layard 2005). That is, satisfaction with SOL contributes to overall happiness in life (life satisfaction). On the other hand, materialism refers to the value individuals place on their material life vis-à-vis other life domains such as social life, leisure life, family life, and spiritual life (Robert and Clement 2007). Further, materialism, may adversely affect life satisfaction because materialistic people allocate much of their time, energy, and resources to the pursuit of material gains, which may come at the expense of gains in other important life domains such as social life, family life, leisure life, and spiritual life (Kasser and Ryan 1993; Sirgy and Wu 2009). In addition, materialism is also a double-edged sword. On the one hand, it may lead to life dissatisfaction through SOL evaluations based on ideal expectations; and on the other hand, it may lead to life satisfaction through SOL evaluations based on ability expectations.

What are the policy implications of this research? This study demonstrates that in relation to life satisfaction, materialism has positive and negative consequences. Public policies should be formulated to minimize the negative effects of materialism and maximize the positive effects. In other words, materialistic people should be encouraged to evaluate their SOL based on ability expectations, not ideal expectations. One can argue that an economic system of meritocracy encourages people to evaluate their lot in life based on ability-related criteria such as performance based on ability (i.e., education, expertise, and experience).

In essence, meritocracy is a system of government or organization wherein appointments are made and responsibilities given based on demonstrated talent and ability (merit), rather than wealth, family connections, class privilege, friends, seniority, popularity or other historical determinants of social position or political power (Wikipedia 2009). The notion that people are evaluated and rewarded based on merit is fundamental in Western economies (Son Hing et al. 2002). Meritocracy becomes part of an employee's contract with the employer, whether formal or psychological, and that the employee's potential for career development and economic rewards is based on their ability and talent demonstrated within their role. Therefore, a clear public policy implication based on our study findings is that public policy should be based clearly on meritocracy. People should be able to learn, through educational, political, and economic institutions, that economic motivation, satisfaction with material life, and ultimately life satisfaction are all linked to meritocracy. 
Future research is encouraged to test alternative models and focus on cross-cultural comparisons. One may hypothesize that causality is reversed. Could it be the case that those who are already happy experience greater satisfaction with their standard of living? Quality-of-life researchers refer to this phenomenon as "top-down spillover" (Diener 1984; Diener et al. 1999; Sirgy 2002). In other words, happy people tend to evaluate their life domains (material life as being one of their life domains) more positively than unhappy people, and vice versa. Could it be that happy people become more economically motivated than unhappy people? In other words, something about happiness makes people more economically motivated, not the other way around. There is some evidence suggesting that happy people tend to experience more vigor, physical strength, emotional energy, and cognitive liveliness than unhappy people (Shirom 2011). This finding is explained using Fredrickson's (2001) broaden-and-build theory that is gaining much acceptance in qualityof-life studies. This theory posits that happiness does have cognitive and motivational consequences in that positive emotions serve to expand mental and physical capability and to heighten achievement motivation.

With respect to cross-cultural comparisons, it may be that certain cultures may place greater value on both materialism and meritocracy, and the theoretical relationships propagated by our model (materialism, frequency of SOL evaluations based on ideal versus ability expectations, satisfaction with material life, economic motivation, and life satisfaction) are likely to be more evident than in cultures that do not place high value on materialism and meritocracy. Although our study involves data collected from various countries (Australia, Bosnia/Herzegovina, Germany, Egypt, Korea, Turkey, and the USA), our focus has been internal rather than external validity. In other words, our goal was to enhance variability in our study constructs rather than to conduct cross-cultural comparisons. Such studies should constitute the next step in conducting programmatic research on this topic.

Future research should also attempt to segment the materialistic segment into those who make SOL evaluations based on ideal versus ability expectations. Our research has focused on demonstrating that making SOL evaluations based on ideal expectations is likely to contribute to life dissatisfaction; and by the same token, making SOL evaluations based on ability expectations is likely to contribute to life satisfaction. Future research should conduct cluster analysis segmenting the highly materialistic people into two segments and test the hypothesis that high materialistic people who make SOL evaluations based on ideal expectations are likely to report lower levels of life satisfaction; and conversely, those who are highly materialistic who make SOL evaluations based on ability expectations are likely to report higher levels of life satisfaction.

Future research could identify under what conditions materialistic people are likely to evaluate their SOL using ideal versus ability standards. We previously alluded to situational prompts such as when exposed to information about the rich and famous (prompt that may evoke ideal standards) versus information related to entrepreneurship (prompt that may evoke ability standards). Future research could investigate the effects of these situational prompts on the frequency of SOL evaluations using ideal versus ability expectations and empirically document the effects of varying situational prompts.

Future research should also examine the effects of other types of expectations that people use in their SOL evaluations. Sirgy (1998) alluded to at least six different types of expectations frequently used in SOL evaluations: ideal, deserved, need-based, past, predictive, and ability-based. Our study focused on the varying effects of ideal versus abilitybased expectation in SOL evaluations. Sirgy theorized that materialistic people are likely 
to frequently use ideal, deserved, and need-based standards, while non-materialistic people frequently use past, predictive, and ability-based expectations. Our study provided evidence that materialistic people frequently use both ideal and ability-based standards in their SOL evaluations. One can hypothesize that people who are high on materialism may use all types of standards (possibly the six different types of standards) more frequently than their non-materialistic counterparts. They may do so as a direct function of situational prompts that may evoke different standards. For example, situational prompts that may evoke ideal standards would be information cues about the rich and famous; prompts evoking deserved standards would be cues related to equity and justice; prompts evoking need-based standards would be cues related to expenses to support a certain lifestyle; prompts evoking past standards would be cues related to one's past history; prompts evoking predictive standards would be cues related to parents' references to one's future economic potential, and finally prompts related to ability standards may involve cues related to the individual level of education, occupation, and professional experience. Future experimental studies may empirically demonstrate the effect of situational prompts on the frequent use of varying standards in SOL evaluations.

Last but not least, our study included a measure of economic motivation that some may be view as confounded with subjective well-being. The emphasis of this measure is the extent to which people strive to attain goals they set in life, economic goals are likely to be very important for most people. Those who do not set goals and are not committed to achieving important goals in life are likely to experience lower subjective well-being. There is much research in goal theory in personality and social psychology that substantiates this point. For a review see Diener (1984) and Diener et al. (1999) for supporting evidence. Future research should employ economic motivation measures that are clearly discriminant from subjective well-being measures.

In sum, we hope that our theoretical model and study findings will encourage future research in this area and promote the ideals of meritocracy as a way to enhance the quality of life for all.

\section{Appendix}

Table 4 Correlations, means, and standard deviations

\begin{tabular}{|c|c|c|c|c|c|c|c|c|}
\hline & 1 & 2 & 3 & 4 & 5 & 6 & Mean & $\mathrm{SD}$ \\
\hline Materialism & 1 & & & & & & 2.60 & 0.84 \\
\hline SOL_Ideal & $0.298^{* *}$ & 1 & & & & & 4.65 & 2.74 \\
\hline SOL_Ability & $0.140^{* *}$ & $0.321 * *$ & 1 & & & & 5.66 & 2.73 \\
\hline Satisfaction with SOL & -0.003 & $-0.161 * *$ & -0.024 & 1 & & & 5.22 & 1.28 \\
\hline Economic motivation & $-0.204 * *$ & -0.045 & $0.086^{* *}$ & $0.163 * *$ & 1 & & 3.43 & 0.92 \\
\hline Life satisfaction & $-0.161^{* *}$ & $-0.117 * *$ & $0.076^{*}$ & $0.514 * *$ & $0.361 * *$ & 1 & 4.84 & 1.23 \\
\hline
\end{tabular}

SOL standard of living, SOL_Ideal ideal-based expectations of SOL, SOL_Ability ability-based expectations of SOL

$* p<0.05 ; * * p<0.01$ 


\section{References}

Anderson, J. J., \& Gerbing, D. J. (1988). Structural equation modeling in practice: A review and recommended two-step approach. Psychological Bulletin, 103, 411-423.

Arndt, J. (1981). Marketing and the quality of life. Journal of Economic Psychology, 1, 283-301.

Bagozzi, R. P., \& Heatherton, T. F. (1994). A general approach to representing multifaceted personality constructs: Application to state self-esteem. Structural Equation Modeling, 1, 35-67.

Bandura, A. (1997). Self-efficacy: The exercise of control. New York: Freeman.

Baudrillard, J. (1997). The consumer society. London: Sage.

Belk, R. W. (1984). Three scales to measure constructs related to materialism: Reliability, validity, and relationships to measures of happiness. In T. Kinner (Ed.), Advances in consumer research (Vol. 11, pp. 291-297). Provo, UT: Association for Consumer Research.

Belk, R. W. (1985). Materialism: Trait aspects of living in the material world. Journal of Consumer Research, 12, 265-280.

Belk, R. W. (1988). Possessions and the extended self. Journal of Consumer Research, 15, 139-168.

Belk, R. W. (1989). Effects of identification with comic book heroes and villains of consumption on materialism among former comic book readers. Advances in Consumer Research, 16, 414-419.

Bentler, P. M. (1990). Comparative fit indexes in structural models. Psychological Bulletin, 107, $238-246$.

Bentler, P. M. (1995). EQS structural equations program manual. Encino, California: Multivariate Software.

Britton, E. (2010). Consumption: New key to Chinese growth. The China Business Review, 37, 26-30.

Browne, M. W., \& Cudeck, R. (1989). Single sample cross-validation indices for covariance structures. Multivariate Behavioral Research, 24, 445-455.

Bunker, S. G., \& Ciccantell, P. S. (2003). Generative sectors and the new historical materialism: Economic ascent and the cumulatively sequential restructuring of the world economy. Studies in Comparative International Development, 37, 3-20.

Burroughs, J. E., \& Rindfeisch, A. (2002). Materialism and well-being: A conflicting value perspectives. Journal of Consumer Research, 29, 348-370.

Campbell, A., Converse, P. E., \& Rodgers, W. L. (1976). The quality of America life. New York: Russell Sage Foundation.

Cherrington, D. (1980). The work ethic: Working values and values that work. New York: AMA-COM.

Churchill, G. A. (1979). A paradigm for developing better measures of marketing constructs. Journal of Marketing Research, 16, 64-73.

Dawson, S., \& Bamossy, G. (1991). If we are what we have, what are we when we don't have? An exploratory study of materialism among expatriate-Americans. Journal of Social Behavior and Personality, 6, 363-384.

Diener, E. (1984). Subjective well-being. Psychological Bulletin, 95, 542-575.

Diener, E., \& Fujita, F. (1995). Resources, personal strivings, and subjective well-being: A nomothetic and idiographic approach. Journal of Personality and Social Psychology, 68, 926-935.

Diener, E., Suh, E. M., Lucas, R. E., \& Smith, H. L. (1999). Subjective well-being: Three decades of research. Psychological Bulletin, 125, 276-302.

Fata-Villafranca, F., \& Saura-Bacaicoa, D. (2004). Understanding the demand-side of economic change: A contribution to formal evolutionary theorizing. Economics of Innovation and New Technology, 13, 695-710.

Fernandez, J. E. (2007). Resource consumption of new urban construction in China. Journal of Industrial Ecology, 11, 99-115.

Fornell, C., \& Larcker, D. F. (1981). Evaluating structural equation models with unobservable variables and measurement errors. Journal of Marketing Research, 18, 39-50.

Fredrickson, B. L. (2001). The role of positive emotions in positive psychology: The broaden-and-build theory of positive emotions. American Psychologist, 56, 219-226.

Fujita, F. (2008). The frequency of social comparison and its relation to subjective well-being. In M. Eid \& R. J. Larsen (Eds.), The science of subjective well-being (pp. 239-257). New York: Guilford Press.

Furnham, A. (1990). The Protestant work ethic: The psychology of work-related beliefs and behaviors. London: Routledge.

Gerdtham, U.-G., \& Johannesson, M. (2001). The relationship between happiness, health, and socio-economic factors: Results based on Swedish microdata. Journal of Socio-Economics, 30, 553-557.

Hayo, B., \& Seifert, W. (2003). Subjective economic well-being in Eastern Europe. Journal of Economic Psychology, 24, 329-348.

Joreskog, K., \& Sorbom, D. (1984). Lisrel VI user's guide. Mooresville, Indiana: Scientific Software International. 
Joreskog, K., \& Sorbom, D. (2006). Lisrel 8.80 user's guide. Lincolnwood, Illinois: Scientific Software International.

Kasser, T., \& Ryan, R. M. (1993). A dark side of the American dream: Correlates of financial success as a central life aspiration. Journal of Personality and Social Psychology, 65, 410-422.

Keng, K. A., Jung, K., Jiuan, T. S., \& Wirtz, J. (2000). The influence of materialistic inclination on values, life satisfaction, and aspirations: An empirical analysis. Social Indicators Research, 49, 317-333.

Kilbourne, W. E., McDonagh, P., \& Prothero, A. (1997). Sustainable consumption and the quality of life: A macromarketing challenge to the dominant social paradigm. Journal of Macromarketing, 17, 4-21.

La Barbera, P. A., \& Gurhan-Canli, Z. (1997). The role of materialism, religiosity, and demographics in subjective well-being. Psychology \& Marketing, 14, 71-97.

Larsen, V., Sirgy, M. J., \& Wright, N. D. (1999). Materialism: The construct, measures, antecedents, and consequences. Academy of Marketing Studies Journal, 3, 75-107.

Layard, R. (2005). Happiness: Lessons from a new science. New York: The Penguin Press.

Layton, R. A. (2009). On economic growth, marketing systems, and the quality of life. Journal of Macromarketing, 29, 349-362.

McClelland, D. C. (1961). The achieving society. Princeton, New Jersey: Van Nostrand.

McClelland, D. C., \& Winter, D. J. (1969). Motivating economic achievement. New York: The Free Press.

Ogden, H. J., \& Venkat, R. (2001). Social comparison and possessions: Japan vs. Canada. Asia Pacific Journal of Marketing and Logistics, 13, 72-84.

Peiro, A. (2006). Happiness, satisfaction, and socio-economic conditions: Some international evidence. Journal of Socio-Economics, 35, 348-365.

Pinquart, M., \& Sörensen, S. (2000). Influences of socio-economic status, social network, and competence on subjective well-being in later life: A meta-analysis. Psychology and Aging, 15, 187-224.

Richins, M. L. (1987). Media, materialism, and human happiness. In M. Wallendorf \& P. Anderson (Eds.), Advances in consumer research (Vol. 14, pp. 352-356). Ann Arbor, Michigan: Association for Consumer Research.

Richins, M. L. (1994a). Special possessions and the expression of material values. Journal of Consumer Research, 21, 531-552.

Richins, M. L. (1994b). Valuing things: The public and private meanings of possessions. Journal of Consumer Research, 21, 504-521.

Richins, M. L., \& Dawson, S. (1992). A consumer values orientation for materialism and its measurement: Scale development and validation. Journal of Consumer Research, 19, 303-316.

Richins, M. L., \& Rudmin, F. W. (1994). Materialism and economic psychology. Journal of Economic Psychology, 15, 217-231.

Robbins, S. B., \& Patton, M. J. (1985). Self-psychology and career development: Construction of the superiority and goal instability scales. Journal of Counseling Psychology, 32, 221-231.

Robert, J. A., \& Clement, A. (2007). Materialism and satisfaction with overall quality of life and eight life domains. Social Indicators Research, 82, 79-92.

Roberts, J. A., Tanner, J. F., Jr., \& Manolis, C. (2005). Materialism and the family structure-stress relation. Journal of Consumer Psychology, 15, 183-190.

Schor, J. B. (1998). The overspent American: Why we want what we don't need/upscaling, downshifting, and the new consumer. New York: Harper Perennial/Basic Books.

Scitovsky, T. (1986). Human desire and economic satisfaction. Brighton: Wheatsheaf.

Seligman, M. E. P. (1998). Learned optimism. New York: Pocket Books.

Seligman, M. E. P. (2002). Authentic happiness. New York: Freeman Press.

Shirom, A. (2011). Vigor as a positive affect at work: Conceptualizing vigor, its relations with related constructs, and its antecedents and consequences. Review of General Psychology, 15, 50-64.

Sirgy, M. J. (1998). Materialism and quality of life. Social Indicators Research, 43, 227-260.

Sirgy, M. J. (2002). The psychology of quality of life. Dordrechet, Netherlands: Springer.

Sirgy, M. J., Lee, D.-J., Kosenko, R., Meadow, H. L., Rahtz, D., Cicic, M., et al. (1998). Does television viewership play a role in the perception of quality of life? Journal of Advertising, 27, 125-142.

Sirgy, M. J., \& Wu, J. (2009). The pleasant life, the engaged life, and the meaningful life: What about the balanced life? Journal of Happiness Studies, 10, 183-196.

Son Hing, L. S., Bobocel, D. R., \& Zanna, M. P. (2002). Meritocracy and opposition to affirmative action: Making concessions in the face of discrimination. Journal of Personality and Social Psychology, 83, 493-509.

Steiger, J. H., \& Lind, J. C. (1980, May). Statistically based tests for the number of factors. Paper presented at the annual spring meeting of the Psychometric Society, Iowa City, Iowa.

Szymanski, D. M., \& Henard, D. H. (2001). Customer satisfaction: A meta-analysis of the empirical evidence. Journal of the Academy of Marketing Science, 29, 16-35. 
Tian, K. T., Bearden, W. O., \& Hunter, G. L. (2001). Consumers' need for uniqueness: Scale development and validation. Journal of Consumer Research, 28, 50-66.

Van Boven, L., \& Ashworth, L. (2007). Looking forward, looking back: Anticipation is more evocative than retrospection. Journal of Experimental Psychology, 136, 289-300.

West, S. G., Finch, J. F., \& Curran, P. J. (1995). Structural equation models with non-normal variables: Problems and remedies. In R. H. Hoyle (Ed.), Structural equation modeling: Concepts, issues, and applications (pp. 56-75). Thousand Oaks, California: Sage.

Wikipedia (2009). Meritocracy. Available at: http://en.wikipedia.org/wiki/Meritocracy. Accessed 22 June 2009.

Winkelmann, L., \& Winkelmann, R. (1998). Why are the unemployed so unhappy? Evidence from panel data. Economica, 65, 1-15.

Winter-Ebmer, R. (1994). Motivation for migration and economic success. Journal of Economic Psychology, 15, 269-284.

Wong, N., Rindfleisch, A., \& Burroughs, J. E. (2003). Do reverse-worded items confound measures in crosscultural consumer research? The case of the material values scale. Journal of Consumer Research, 30, 72-91.

Wright, N. D., \& Larsen, V. (1993). Materialism and life satisfaction: A meta-analysis. Journal of Consumer Satisfaction, Dissatisfaction and Complaining Behavior, 6, 158-165. 